\title{
Transcatheter aortic valve replacement: Can we get through the turbulence?
}

\author{
Jason J. Han, MD, and Pavan Atluri, MD
}

\footnotetext{
From the Division of Cardiovascular Surgery, Department of Surgery, University of Pennsylvania, Philadelphia, $\mathrm{Pa}$.

Disclosures: Authors have nothing to disclose with regard to commercial support.

Received for publication July 12, 2018; accepted for publication July 13, 2018; available ahead of print Aug 14 2018.

Address for reprints: Pavan Atluri, MD, Division of Cardiovascular Surgery, Hospital of the University of Pennsylvania, 3400 Spruce St, 6 Silverstein Pavilion, Philadelphia, PA 19104 (E-mail: Pavan.Atluri@uphs.upenn. edu).

J Thorac Cardiovasc Surg 2018;156:1849-50

$0022-5223 / \$ 36.00$

Copyright (C) 2018 by The American Association for Thoracic Surgery

https://doi.org/10.1016/j.jtcvs.2018.07.035
}

The field of valvular surgery is amidst a rapid paradigm shift toward minimally invasive platforms, with transcatheter aortic valve replacement (TAVR) at its forefront. Originally indicated for those at a too-high risk to undergo surgical aortic valve replacement, TAVR is being performed on increasingly younger and healthier patients. ${ }^{1-3}$ This progression is predicated on the crucial assumption that TAVR is, or at least will become with future iterations, just as durable an option for patients as surgical aortic valve replacement while carrying a fraction of its perioperative risks. As Hatoum and colleagues $^{4}$ allude to in this edition of the Journal, this is fundamentally an engineering challenge. As is true with surgical aortic valve replacement, improving the durability of TAVR is a matter of optimizing flow patterns to be as physiologically accurate as possible. With TAVR, there is a greater challenge because of the unpredictability of deploying a stent valve inside a heavily diseased valve and root. In addition, other risk factors that comprise atherogenic or thrombogenic milieu, such as a dysmetabolic profile, may further predispose patients toward hemodynamic deterioration. ${ }^{5,6}$

In their reductionist approach consisting of 4 simple setups-a combination of SAPIEN3 (Edwards Lifesciences Corporation, Irvine, Calif) and Medtronic Evolut (Medtronic plc, Minneapolis, Minn) valves in both an idealized orifice and an anatomically realistic configuration-Hatoum and colleagues ${ }^{4}$ enable readers to distill several key insights. One, the ideal performance of any valve does not necessarily translate to in situ or in vivo settings and should always be discerned. Two, certain hemodynamic findings are clearly related to structural predispositions and can be predictable to an extent. Although it is still too early to interpret these indices clinically, performance of valves in patient-specific anatomy may be possible to simulate in the future with the

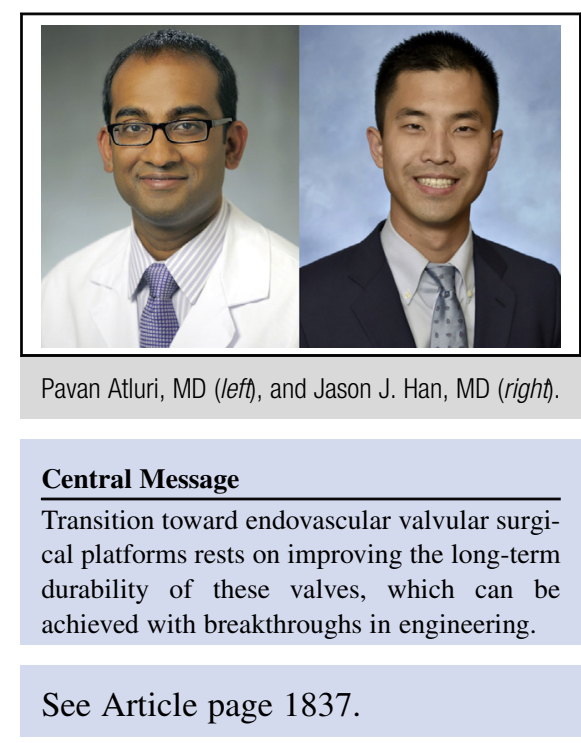

advent of more advanced 3-dimensional imaging and printing. The strength of this study is in its multidimensional analysis of each apparatus with respect to hemodynamic parameters, leaflet kinematics, shear stress, flow turbulence, and velocity. We come to understand these parameters not only conceptually but also visually with the aid of impressive figures and videos. We can see the degree of leaflet coaptation or deformation at various stages of the cardiac cycle. We can see turbulence or velocity in relation to the structure of each type of stent valve, clarifying for many what had been abstract differences. Although small, these minor differences inevitably compound through the course of thousands of cardiac cycles into hemodynamically significant findings. For clinicians and scientists alike, these insights will surely spark further investigations. The inherent limitation of this in vitro analysis is its inability to account for longitudinal remodeling in the aortic annulus and the ventricles, which may further discern the differences in the valves' flow profiles. ${ }^{7,8}$

Hatoum and colleagues ${ }^{4}$ deserve our congratulations on this elegant contribution. From clinical trials containing thousands of patients, it brings us back again to the simplicity of a single aortic annulus, allowing a thorough fundamental analysis of valve function. In the field of TAVR, the synergy between the clinical and the mathematical is inevitable and should continue to be fostered. 


\section{References}

1. Little SH, Oh JK, Gillam L, Sengupta PP, Orsinelli DA, Cavalcante JL, et al. Selfexpanding transcatheter aortic valve replacement versus surgical valve replacement in patients at high risk for surgery: a study of echocardiographic change and risk prediction. Circ Cardiovasc Interv. 2016;9:e003426.

2. Adams DH, Popma JJ, Reardon MJ, Yakubov SJ, Coselli JS, Deeb GM, et al. Transcatheter aortic-valve replacement with a self-expanding prosthesis. $N$ Engl J Med. 2014;370:1790-8.

3. Leon MB, Smith CR, Mack MJ, Makkar RR, Svensson LG, Kodali SK, et al. Transcatheter or surgical aortic-valve replacement in intermediate-risk patients. N Engl J Med. 2016;374:1609-20.

4. Hatoum H, Yousefi A, Lilly S, Maureira P, Crestanello J, Dasi LP. An in vitro evaluation of turbulence after transcatheter aortic valve implantation. J Thorac Cardiovasc Surg. 2018;156:1837-48.
5. Salaun E, Mahjoub H, Dahou A, Mathieu P, Larose É, Després JP, et al. Hemodynamic deterioration of surgically implanted bioprosthetic aortic valves. J Am Coll Cardiol. 2018;72:241-51.

6. Makkar RR, Fontana G, Jilaihawi H, Chakravarty T, Kofoed KF, De Backer O, et al. Possible subclinical leaflet thrombosis in bioprosthetic aortic valves. $N$ Engl J Med. 2015;373:2015-24.

7. Al-Hawwas M, Marmagkiolis K, Mehta JL. The impact of transcatheter aortic valve implantation and surgical aortic valve replacement on left ventricular remodeling. Am J Cardiol. 2017;120:1198-202.

8. Oh JK, Little SH, Abdelmoneim SS, Reardon MJ, Kleiman NS, Lin G, et al. Regression of paravalvular aortic regurgitation and remodeling of self-expanding transcatheter aortic valve: an observation from the CoreValve U.S. Pivotal trial. J Am Coll Cardiol. Cardiovasc Imaging. 2015; $8: 1364-75$. 